Systematic Review

\title{
Predictive Risk Factors of Smartphone Addiction in Adolescents: A Systematic Review
}

\author{
Abdul Fauzi' ${ }^{1}$ Ah. Yusuf ${ }^{1}$ and Mundakir Mundakir ${ }^{2}$ \\ 1 Faculty of Nursing, Universitas Airlangga, Surabaya, East Java, Indonesia \\ ${ }^{2}$ Faculty of Health Science, Universitas Muhammadiyah Surabaya, Indonesia
}

\begin{abstract}
Introduction: Smartphone addiction often occurs in adolescents. The purpose of this systematic review was to identify the predictors of smartphone addiction in adolescents.
\end{abstract}

Methods: The method used in this systematic review consisted of 5 stages: (1) the identification of the instruments used in the literature (database search); (2) the identification of the relevant literature based on the title and abstract; (3) the inclusion and exclusion criteria; (4) getting the full-text literature and (5) grading based on the literature component and the analysis of the selected instruments. The databases used in the literature search were Scopus, PubMed, Science Direct and Springer Link from 2013 2018. The criteria for the included articles were that they used a crosssectional design and involved adolescents as the sample.

Results: 17 of 829 articles met the inclusion criteria. The predictors of smartphone addiction were broadly divided into 3 , namely personal factors, interpersonal factors and behavioral factors. These 3 factors are related to one another.

Conclusion: It is necessary to do further research within a case-control study to strengthen this systematic review.

\section{ARTICLE HISTORY}

Received: December 26, 2019

Accepted: December 31, 2019

\section{KEYWORDS}

addiction; adolescents; risk factors; smartphone

\section{CONTACT}

Abdul Fauzi

$\triangle$ abdul.fauzi-2017@fkp.unair.ac.id

$\fallingdotseq$ Faculty of Nursing, Universitas

Airlangga, Surabaya, Indonesia

Cite this as: Fauzi. A., Yusuf, A., \& Mundakir, M. (2019). Predictive Risk Factors of Smartphone Addiction in Adolescents: A Systematic Review. Jurnal Ners, 14(3si), 236-241. doi:http://dx.doi.org/10.20473/in.v14i3(si).17110

\section{INTRODUCTION}

Smartphone addiction is a problem that has received serious attention in recent years (H. Lee, Kim, \& Choi, 2017). Smartphone addiction is more common in adolescents than in adults (Haug et al., 2015). This is inseparable from the culture inherent in Asian countries regarding adolescents and smartphone use (BBC, 2015). Based on the research conducted by Lee (2017) in South Korea, the prevalence of smartphone addiction was found to total $35 \%$ of adolescents (C. Lee \& Lee, 2017). Problems with smartphone use more often occur from social networking sites, online games and chatting applications (S. J. Lee, Lee, \& Lee, 2016). The influence of smartphone addiction in adolescents was found to deplete academic performance(Samaha \& Hawi, 2016).

The number of smartphone users in Indonesia is one of the largest in Asia. The country ranked second after China, with the total of 100 million smartphone users (Kominfo, 2014). Adolescents comprise 30\% out of $80 \%$ of the total citizen in Indonesia (the percentage of internet users out of the total population) (Kominfo, 2014). Previous research conducted by Palupi (HUBUNGAN KETERGANTUNGAN SMARTPHONE TERHADAP KECEMASAN PADA MAHASISWA FAKULTAS DIPONEGOR0," 2018) showed that as many as $71.5 \%$ of adolescent smartphone-users were moderately addicted, $16.8 \%$ were mildly addicted and $11.7 \%$ were severely intolerance.

Smartphone addiction in adolescents will have a negative effect on psychology and daily activities. Evidence of the bad influence of smartphone addiction is the cause of decreased sleep quality, decreased academic achievement, depression and conflict (Lian, You, \& Huang, 2016). Another picture of teenage smartphone addiction is aggressive policies, low prices and poor communication with others (J. Lee et al., 2018). The main prevention in reducing smartphone addiction in adolescents is by increasing self-control in the most important way in order to identify the factors that cause smartphone addiction (Sun, Liu and Yu, 2018). The purpose of this 
systematic review was to find out the predictors of smartphone addiction.

\section{MATERIALS AND METHODS}

This systematic review followed the Preferred Reporting Item For Systematic Reviews and MetaAnalyzes (PRISMA) guidelines (Liberati et al., 2009b).

\section{Search strategy}

The search for potential articles was conducted through electronic databases, namely Scopus, PubMed, ScienceDirect and Springer Link. The papers included a human model and were published in the English language. Those that were published between 2013 - 2018 were included in this review. The keywords used were "smartphone addiction" AND "adolescent" OR "factor" OR "predictor". Furthermore, cross-sectional research related to smartphone addiction was also searched for. Only the studies that were related to smartphone addiction in adolescents were included.

\section{Inclusion and Exclusion Criteria}

The inclusion criteria in the systematic review included the research design, research population and research outcomes. The research design here was a cross-sectional design. The population in this study was adolescents who experienced smartphone addiction. All of the variables were related to the incidence of smartphone addiction in adolescents.

\section{Data Extraction and Quality of Appraisal}

A total of 16 studies were selected and reviewed that met all of the eligibility criteria. The standard protocol used as a guideline for this systematic review was PRISMA as shown in Figure 1 below (Liberati et al., 2009a). The steps taken included (1) the removal of duplications, (2) the independent examination of the titles, abstracts and keywords, then removing the excerpts that were not relevant in accordance with the inclusion criteria (3), thetitles and abstracts that appear to meet the inclusion criteria and that were in accordance with the objectives of the systematic review were chosen if the journal had full text available and (4) the selection of cross-sectional study articles to reduce the risk of bias.

The quality assessment of the articles used the JBI critical appraisal tools. Systematic reviews that combine the process of critique and the assessment of the research evidence aim to assess the methodological quality of a given study and seek to determine the extent to which a study has discussed the possible bias in the criteria, research subjects, exposure measured, confounding factors, outcome measures and the statistical analysis used. There were as many as 8 items in the list of JBI critical appraisal tools for cross-sectional studies. The choice of answers consisted of "yes", "no", "unclear" and "not applicable". The allocation of each article was based on how many "yes" or "no" answers, which was very good. This assessment was combined with that of the other reviewers. If there were differences of opinion among the reviewers then this was completed in the next discussion phase. The allocation of scores for each article reviewed was based on how many "yes" or more answers were given, referring to the quality of the article that was very good. The purpose of this quality assessment was not to distinguish between the different levels of quality for the articles but to refer to systematic and standard processes that can help to provide high-quality reviews based on the existing topics.

\section{RESULTS}

\section{Study selection}

Figure 1 summarizes the search results and the selection of the studies following the PRISMA guidelines (Liberati et al., 2009b). The selection of journals based on the keywords used produced 829 articles; 664 articles found after duplication screening. Following this, 542 were eliminated because of being irrelevant studies based on their titles and abstracts. A total of 122 articles with full text were taken and 106 were studies excluded because they did not meet the inclusion criteria. The results of the 16 studies were used to carry out a systematic review.

\section{Study characteristic}

Regarding teh 16 included studies, 12 were conducted in Asia and 4 were conducted in Europe. The included studies involved 1301 participants, consisting of 332 (25\%) men and 969 (75\%) women. The majority of studies recruited participants aged 10 to 29 years old. All of the studies adopted a crosssectional design. The total number of respondents in the selected literature were 29,534 and the respondents were aged between 10-29 years old.

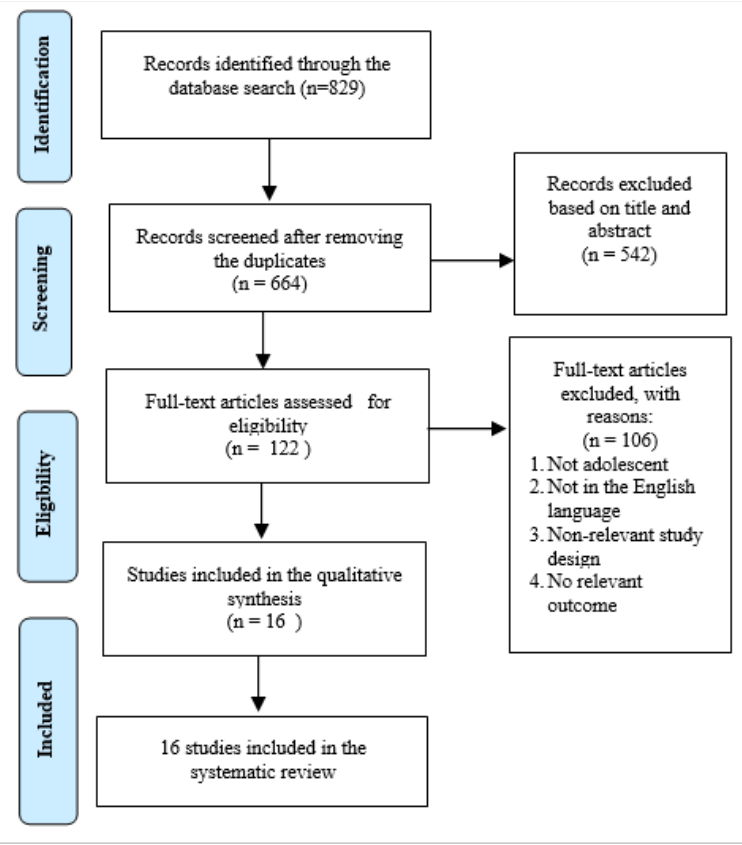

Figure 1. Literature search following the PRISMA diagram 


\section{Risk of bias}

The risk of bias judgment for each paper used the JBI appraisal tools. The results of the critical appraisal shows that 10 papers $(62.5 \%)$ were considered to have a low risk of bias, 4 (25\%) had a moderate risk of bias and $2(12,5 \%)$ had a high risk of bias. The less obvious inclusion and exclusion criteria were the causes of the first source of bias. Other than that, the confounding factors have not been identified as the other risk factors for bias.

\section{Result of Synthesis}

\section{Personal}

The personal factors in smartphone addiction include personality (Cocorada, Maican, Cazan, \& Maican, 2018; Gao, Xiang, Zhang, Zhang, \& Mei, 2017), psychological problems such as anxiety, depression (Chen et al., 2017; Long et al., 2016), somatization and hostility symptoms (Firat et al., 2018), quality of life (Kumcagiz, 2019), self-esteem (J. Lee et al., 2018), stress (Haug et al., 2015; Long et al., 2016) and income (Chen et al., 2017).

Based on the research conducted by Cocorada (2018)(Cocorada et al., 2018) on adolescents in Romania, they stated that personalities with high neuroticism will increase the risk factors for smartphone addiction. High neuroticism tends to lead to difficulties when building relationships with other people. Neurotics are not able to communicate with the people around them, so this will cause depression and decrease their quality of life (Gao et al., 2017).

According to Chen's (2017) (Chen et al., 2017) research, the risk factors for smartphone addiction significantly include anxiety, depression and sleep quality. The use of smartphones in adolescents who experience anxiety is done as an effort to reduce or eliminate the feelings of anxiety and depression in order to get pleasure (Long et al., 2016). Anxiety and depression also affect smartphone addiction through being able to adjust the frequency of the use of the smartphone (Elhai, Levine, Dvorak, \& Hall, 2017). Addiction will increase along with the frequency of using the smartphone (Cocoradă, Maican, Cazan, \& Maican, 2018). Psychological problems such as anxiety and depression are also related to emotional intelligence and coping styles (Sun, Liu, \& Yu, 2019). Adolescents with low emotional intelligence and destructive coping styles will not be able to solve the problems faced day to day and they will seek to improve the behaviors that are considered to make themselves happy like playing on the smartphone (Sun et al., 2019).

Smartphone addiction is also found in teens with low self-esteem. The use of smartphones is used as an effort to gain intimacy in the virtual world as an effort to build new self-confidence (J. Lee et al., 2018). Besides that, quality of life was found to be negatively correlated with smartphone addiction. The use of smartphones is used as an effort to improve the quality of life (Kumcagiz, 2019).

Another personal factor is income. Based on the research conducted by Long et al. (2016)(Long et al.,
2016) on teens in China, smartphone addiction is related to the family income. This is related to the lifestyle of the adolescents. Adolescents with a high family income tend to experience smartphone addiction. There are no financial restrictions that tend to increase the addictive behavior in adolescents (Long et al., 2016).

\section{Interpersonal}

The interpersonal factors that cause smartphone addiction include their relationships with their parents (Firat et al., 2018; C. Lee \& Lee, 2017) and social support such as their school life (C. Lee \& Lee, 2017).

Smartphone addiction will increase in teens who have problems with their parents. Adolescents who have experienced domestic violence and parental addiction will increase their likelihood of smartphone addiction because of their exposure to the surrounding environment (Kim \& Koh, 2018). In addition, smartphone addiction occurs in students who are far from their parents (Haug et al., 2015). The loss of the role of the parents when it comes to controling adolescent behavior increases the risk of smartphone addiction (C. Lee \& Lee, 2017).

Interpersonal relations with their peers whenn carrying out activities in school can improve individual satisfaction. Individuals who take part in school activities with their friends will prefer real life rather than busying themselves with smartphones (C. Lee \& Lee, 2017). Based on the research conducted by Lee and Lee (2017)(C. Lee \& Lee, 2017) on adolescents in Korea, it was found that good peer support would reduce the smartphone addiction rate in adolescents. Therefore, maintaining good relationships with their peers and schoolmates can prevent smartphone addiction in adolescents. Low self-esteem also mediates peer relationships and smartphone addiction. Self-esteem becomes a form of social control for determining good relations between peers (Y. Li, Wang, Yin, Li, \& Li, 2018).

\section{Behavior}

Behavior in this systematic review included the duration and frequency of smartphone use (Cha \& Seo, 2018; Cocorada et al., 2018), the process of smartphone use (Chen et al., 2017; Cocoradă et al., 2018; Elhai et al., 2017; S. J. Lee et al., 2016), avoidant attachment (Kim \& Koh, 2018), positive attitudes toward smartphone use (Cocorada et al., 2018), motivation (C. Lee \& Lee, 2017), reporting lower physical activity (Haug et al., 2015), aggressive behavior (J. Lee et al., 2018) and the need to belong (Wang et al., 2017).

The behavior of smartphone use is related to smartphone addiction (Elhai et al., 2017). A longer duration of smartphone use will increase the risk of addiction (Cha \& Seo, 2018). Increased smartphone usage is also influenced by the motivation behind the smartphone use (C. Lee \& Lee, 2017). The motive for using smartphones is, for men, to play games, watch videos and listen to music. For women, the motive for using smartphones is more related to the function of 
communication and social media (Chen et al., 2017). In addition, the assumption of smartphones being a need increases the risk of smartphone addiction. This need also moderates peer relationships with smartphone addiction. The high demand for smartphones will assume that smartphones have a positive impact, especially in relation to improving their social relationships with their peers (Wang et al., 2017). This statement is consistent with the research conducted by Cocoradă (2018), in that a positive assessment of smartphones is positively related to smartphone addiction. The duration of the smartphone usage, the positive assessment of smartphone usage and the motive behind using the smartphone also mediates the relationship between personality and smartphone addiction (Cocorada et al., 2018).

Based on the research by Haug (2015), smartphone addiction is more common in adolescents with little physical activity. Reduced physical activity can be caused by the avoidance of other people. This is consistent with the research conducted by Kim (2018), indicating that avoidant attachments are done to keep a distance from others and to avoid close relationships. Increased activity actually occurs in terms of smartphone use such as user applications and online sites (J. Lee et al., 2018).

\section{DISCUSSION}

This systematic review aimed to identify the predictors of smartphone addiction in adolescents. The articles used a homogeneous research design. There are several findings related to the predictor factor of smartphone addiction. Smartphone addiction can be divided into 3 , namely personal factors, interpersonal relationships and behavior. There are several important findings regarding the predicting factors of smartphone addiction in adolescents that will now be discussed in detail.

Interpersonal factors such as peer support both from their peers and parents greatly influence the personality and abilities of the adolescents. Adolescents who have bad relationships with their peers will look for something to meet their interpersonal needs (C. Lee \& Lee, 2017). In addition, the role of the parents is very important. Parents who always give attention and affection and who supervise the adolescents will prevent the adolescents from reactions such as smartphone addiction. Conversely, adolescents who are always blamed by their parents and parents who have great hopes for their children will hinder the growth and development of the adolescents. Young children can become depressed both physically and psychologically. Adolescents can experience disorders such as anxiety, depression and low selfesteem, which can go on to affect the coping system and personality of the adolescents (X. Li, Li, \& Newman, 2013).

Personalities with high neuroticism will increase the risk factors for smartphone addiction (Gao et al.,
2017). A closed individual will feel anxious when there is no access to the smartphone (Cocorada et al., 2018). This is because a smartphone is a tool to meet their needs (Wang et al., 2017). Low emotional intelligence and destructive coping systems will not be able to effectively overcome emotional problems. This low emotional intelligence also increases the interpersonal problems in the individuals. Adolescents with low emotional intelligence and emotion-focused coping styles will experience smartphone addiction in an effort to meet their social needs. They will more often use the internet facilities of smartphones as a way to fulfil their social needs anytime and anywhere (Sun et al., 2019).

Motivation, the attitude related to and the duration of smartphone use will mediate the personal factors concerning smartphone addiction. Strong motivation lies at the core of the problem at hand but there may be different contributions in terms of different abilities and opportunities within different situations (Michie, van Stralen, \& West, 2011). The ability to engage in behavior also influences the motivation to be involved in it.

A systematic review of the factors that cause smartphone addiction started from the interpersonal factors and personal factors, through to adolescent behavior. The limitations of this study do not present a risk bias table and some of the studies do not describe in detail the confounding factors in each study. In addition, there were several journals that were difficult to read.

\section{CONCLUSION}

This systematic review explains that smartphone addiction is influenced by personal, interpersonal and behavioral factors.

The interpersonal factors related to the people around them will trigger smartphone addiction. This is exacerbated if the adolescents have problems within themselves such as coping, anxiety, depression, low self-esteem, poor quality of life and a lack of emotional intelligence. The inability of adolescents to overcome their problems will increase their motivation and excessive use of smartphones. Studies with case-control are needed to strengthen these systematic results.

\section{REFERENCES}

BBC. (2015). Asia's smartphone addiction.

Cha, S. S., \& Seo, B. K. (2018). Smartphone use and smartphone addiction in middle school students in Korea: Prevalence, social networking service, and game use. Health Psychology Open. https://doi.org/10.1177/2055102918755046

Chen, B., Liu, F., Ding, S., Ying, X., Wang, L., \& Wen, Y. (2017). Gender differences in factors associated with smartphone addiction: A cross-sectional study among medical college students. $B M C$ Psychiatry. https://doi.org/10.1186/s12888-0171503-z

Cocorada, E., Maican, C. I., Cazan, A. M., \& Maican, M. . 
(2018). Assessing the smartphone addiction risk and its associations with personality traits among adolescents. Children and Youth Services Review 93, 345-354.

Cocoradă, E., Maican, C. I., Cazan, A. M., \& Maican, M. A. (2018). Assessing the smartphone addiction risk and its associations with personality traits among adolescents. Children and Youth Services Review. https://doi.org/10.1016/j.childyouth.2018.08.00 6

Elhai, J. D., Levine, J. C., Dvorak, R. D., \& Hall, B. J. (2017). Non-social features of smartphone use are most related to depression, anxiety and problematic smartphone use. Computers in Human Behavior.

https://doi.org/10.1016/j.chb.2016.12.023

Fırat, S., Gül, H., Sertçelik, M., Gül, A., Gürel, Y., \& Kılıç, B. G. (2018). The relationship between problematic smartphone use and psychiatric symptoms among adolescents who applied to psychiatry clinics. Psychiatry Research. https://doi.org/10.1016/j.psychres.2018.09.015

Gao, T., Xiang, Y. T., Zhang, H., Zhang, Z., \& Mei, S. (2017). Neuroticism and quality of life: Multiple mediating effects of smartphone addiction and depression. Psychiatry Research. https://doi.org/10.1016/j.psychres.2017.08.074

Haug, S., Paz Castro, R., Kwon, M., Filler, A., Kowatsch, T., \& Schaub, M. P. (2015). Smartphone use and smartphone addiction among young people in Switzerland. Journal of Behavioral Addictions. https://doi.org/10.1556/2006.4.2015.037

HUBUNGAN KETERGANTUNGAN SMARTPHONE TERHADAP KECEMASAN PADA MAHASISWA FAKULTAS DIPONEGORO. (2018). JURNAL KEDOKTERAN DIPONEGORO.

Kim, E., \& Koh, E. (2018). Avoidant attachment and smartphone addiction in college students: The mediating effects of anxiety and self-esteem. Computers in Human Behavior. https://doi.org/10.1016/j.chb.2018.02.037

Kominfo. (2014). Kementerian Komunikasi dan Informatika.

Kumcagiz, H. (2019). Quality of Life as a Predictor of Smartphone Addiction Risk Among Adolescents. Technology, Knowledge and Learning. https://doi.org/10.1007/s10758-017-9348-6

Lee, C., \& Lee, S. J. (2017). Prevalence and predictors of smartphone addiction proneness among Korean adolescents. Children and Youth Services Review.

https://doi.org/10.1016/j.childyouth.2017.04.00 2

Lee, H., Kim, J. W., \& Choi, T. Y. (2017). Risk factors for smartphone addiction in Korean adolescents: Smartphone use patterns. Journal of Korean Medical Science. https://doi.org/10.3346/jkms.2017.32.10.1674

Lee, J., Sung, M.-J., Song, S.-H., Lee, Y.-M., Lee, J.-J., Cho, S.-M., ... Shin, Y.-M. (2018). Psychological Factors Associated With Smartphone Addiction in South Korean Adolescents. The Journal of Early
Adolescence, 38(3), 288-302. https://doi.org/10.1177/0272431616670751

Lee, S. J., Lee, C., \& Lee, C. (2016). Smartphone addiction and application usage in Korean adolescents: Effects of mediation strategies. Social Behavior and Personality. https://doi.org/10.2224/sbp.2016.44.9.1525

Li, X., Li, D., \& Newman, J. (2013). Parental behavioral and psychological control and problematic internet use among Chinese adolescents: The mediating role of self-control. Cyberpsychology, Behavior, and Social Networking. https://doi.org/10.1089/cyber.2012.0293

Li, Y., Wang, K., Yin, Y., Li, Y., \& Li, S. (2018). Relationships between family resilience, breast cancer survivors' individual resilience, and caregiver burden: A cross-sectional study. International Journal of Nursing Studies. https://doi.org/10.1016/j.ijnurstu.2018.08.011

Lian, L., You, X., \& Huang, J. (2016). Who overuses smartphones? Roles of virtues and parenting style in smartphone addiction among Chinese college students. Computers in Human Behavior, 65, 9299.

https://doi.org/https://doi.org/10.1016/j.chb.20 16.08. 027

Liberati, A., Altman, D. G., Tetzlaff, J., Mulrow, C., Gøtzsche, P. C., Ioannidis, J. P. A., ... Moher, D. (2009a). The PRISMA statement for reporting systematic reviews and meta-analyses of studies that evaluate health care interventions: Explanation and elaboration. PLoS Medicine. https://doi.org/10.1371/journal.pmed.1000100

Liberati, A., Altman, D. G., Tetzlaff, J., Mulrow, C., Gøtzsche, P. C., Ioannidis, J. P. A., ... Moher, D. (2009b). The PRISMA statement for reporting systematic reviews and meta-analyses of studies that evaluate healthcare interventions: explanation and elaboration. BMJ (Clinical Research Ed.). https://doi.org/10.1136/bmj.b2700

Long, J., Liu, T.-Q., Liao, Y.-H., Qi, C., He, H.-Y., Chen, S.B., \& Billieux, J. (2016). Prevalence and correlates of problematic smartphone use in a large random sample of Chinese undergraduates. $B M C$ Psychiatry, 16(1), 408. https://doi.org/10.1186/s12888-016-1083-3

Michie, S., van Stralen, M., \& West, R. (2011). The behaviour change wheel: a new method for characterising and designing behaviour change interventions'. Implementation Science 6, p. 42.

Samaha, M., \& Hawi, N. S. (2016). Relationships among smartphone addiction, stress, academic performance, and satisfaction with life. Computers in Human Behavior. https://doi.org/10.1016/j.chb.2015.12.045

Sun, J., Liu, Q., \& Yu, S. (2019). Child neglect, psychological abuse and smartphone addiction among Chinese adolescents: The roles of emotional intelligence and coping style. Computers in Human Behavior. https://doi.org/10.1016/j.chb.2018.08.032 
Wang, P., Zhao, M., Wang, X., Xie, X., Wang, Y., \& Lei, L. (2017). Peer relationship and adolescent smartphone addiction: The mediating role of selfesteem and the moderating role of the need to belong. Journal of Behavioral Addictions. https://doi.org/10.1556/2006.6.2017.079 